\section{Assessment of abdominal aortic aneurysms by computed tomography}

Most clinically significant abdominal aortic aneurysms are palpable but clinical examination does not normally yield sufficient information for planning management. Plain abdominal radiographs, ${ }^{1}$ angiography, ${ }^{2}$ and ultrasound ${ }^{3}$ are valuable adjuncts but do not reliably show the limits of an aneurysm or give detailed information about its wall. Assessment merely of the size is not sufficient to determine the risk of rupture. We have therefore used computed tomography to obtain more accurate and detailed information about abdominal aneurysms.

\section{Patients, methods, and results}

We studied 25 patients clinically suspected of having an abdominal aortic aneurysm. Computed tomographic scans were made with an EMI CT 5005 Body Scanner with a 20 -s scan time and 13-mm collimator. Slices were taken at $2-\mathrm{cm}$ intervals starting at the xiphisternum. The patients received concurrent intravenous radiographic contrast material by bolus ( $50 \mathrm{ml}$ Conray 420 sodium iothalamate) or by infusion during scanning ( $300 \mathrm{ml}$ Hypaque $25 \%$ sodium diatrizoate), or both. The aorta was easily identified in all the patients and the diagnosis of aneurysm confirmed in 24 out of the 25. At their widest points the aneurysms ranged in size from 3.4 to $11.2 \mathrm{~cm}$ (mean 6.0 ). All the aneurysms had calcium in their walls and the upper and lower extents of the aneurysms were clearly seen. The upper limit was determined by relation to the left renal vein, an important surgical landmark easily identified in scans. The aneurysm extended above this point in two patients. The lumen was visualised separately from the wall in 11 of the 12 patients who received contrast by bolus and infusion but in only two of the 13 who received only bolus or only infusion. Five patients showed thinning of part of the aneurysm wall. In one of them surgery showed that the posterior wall had been completely eroded (figure, a) and in another three the anterior wall was only a few millimetres thick. In these cases rupture
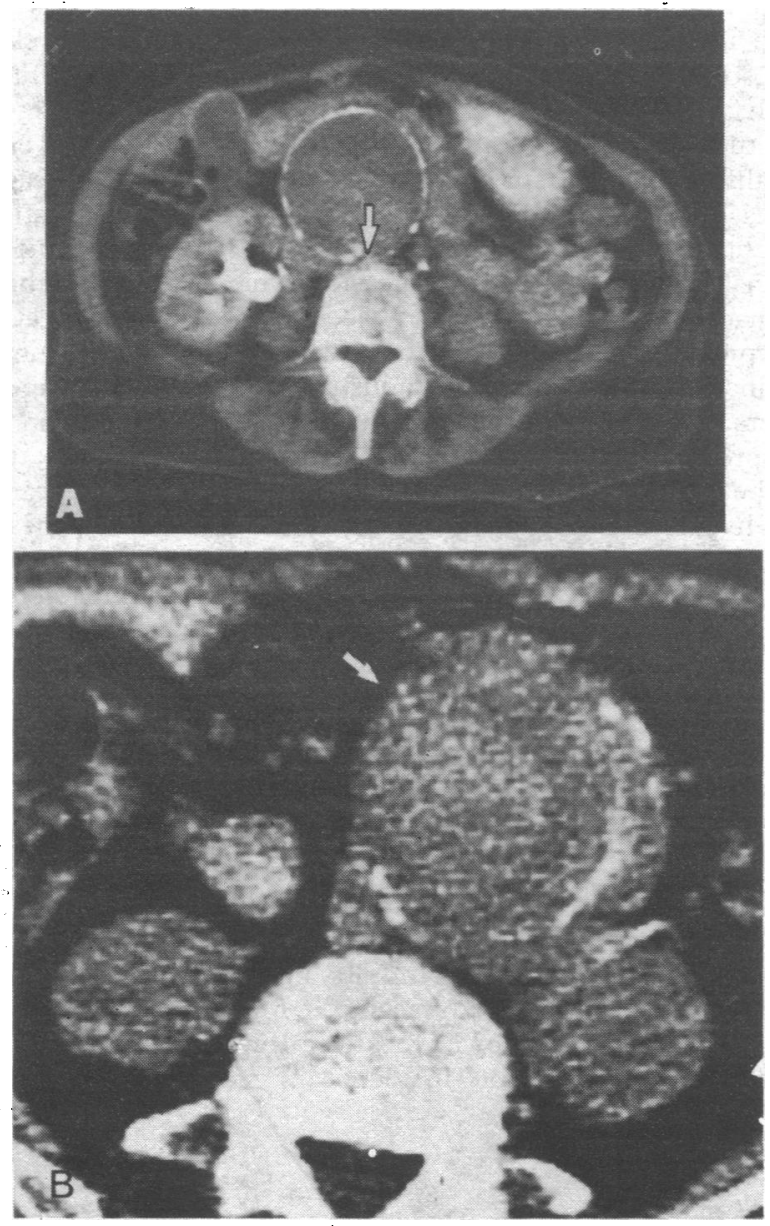

(a) Computed scan of $6.5-\mathrm{cm}$ abdominal aortic aneurysm. Lumen identifiable separately from lining thrombus. Posterior wall eroded (arrow). (b) Asymptomatic 8-cm abdominal aortic aneurysm. Anteromedial wall very thin (arrow). seemed imminent. A fourth patient had thinning of the anterior wall of his asymptomatic aneurysm (figure, b). He died at home a few days after the investigation, probably from ruptured aneurysm. In these patients calcification was absent or its pattern disordered at the point of presumed imminent rupture. All three inflammatory aneurysms examined showed circumferential thickening of the wall outside the calcification. In two patients who had leaked blood from their aneurysm the size and site of the haematoma could be seen.

\section{Comment}

Computed tomography has accurately demonstrated the anatomy of abdominal aortic aneurysms and their adjacent structures. ${ }^{45} \mathrm{We}$ found that by administering an intravenous bolus of contrast material at the beginning and maintaining its concentration by an infusion of contrast during the examination the aortic lumen may be seen in all but the smallest aneurysms. We were thus able to identify those aneurysms whose walls were excessively thinned and those that had leaked. It may therefore be possible to identify aneurysms that are at risk of rupture. Further experience will be required, however, to confirm this possibility. We have also been able clearly to distinguish inflammatory aneurysms from the more usual pattern of atherosclerotic aneurysms.

Computed tomography is the best method of assessing abdominal aortic aneurysms but its cost and limited availability precludes widespread use.

1 Steinberg I, Stein JL. Visualisation of abdominal aortic aneurysms. $A \mathcal{F} R$ $1965 ; 95: 684-95$.

2 Brewster DC, Retana A, Waltman AC, Darling RC. Angiography in the management of aneurysms of the abdominal aorta: its value and safety. $N$ Engl f Med 1975;292:822-5.

3 Bernstein EF, Dilley RB, Goldberger LE, Gosink BB, Leopold GR. Growth rates of small abdominal aortic aneurysms. Surgery 1976;80: 765-73.

4 Perrett LV, Sage MR. Computed tomography of abdominal aortic aneurysms. Aust NZ F Surg 1978;48:275-7.

5 Gomes MN, Hufnagel CA.CT scanning: a new method for the diagnosis of abdominal aortic aneurysms. F Cardiovas Surg 1979;20:511-6.

(Accepted 15 fanuary 1980)

Departments of Surgery and Radiology, St Thomas's Hospital, London SE1 7EH

A E YOUNG, MCHIR, FRCS, senior surgical registrar

M LEA THOMAS, FRCP, FRCR, consultant radiologist

C H WRIGHT, DMRD, FRCR, senior research fellow in radiology

ONE HUNDRED YEARS AGO The correspondent of the Daily News describes some of the scenes witnessed by him at Knock Chapel, the "Irish Lourdes," as it is termed. He writes that the spectacle can only be described as the most saddening he ever saw. The chapel is close to the main road. In front of the gable on which the apparition is said to have been manifested were a number of people, some of them decently clad peasantry, men and women; but others, and these the majority, the most wretched-looking creatures that it is possible to conceive. Some were kneeling in the mud in front of the gable; others were kneeling at the cross over the grave of the founder of the chapel; and many were engaged carefully picking out scraps of cement, which were being carefully treasured by some, who put them in handkerchiefs, while others were in the act of moistening the cement and applying it to whatever part of their body was affected by an ailment. One respectable man, who was not blind, but who probably thought his sight might be improved, was applying the material to his eyes. Others were in the act of catching the water from the slating running over the gable, and moistening the clay with it. Large numbers were walking round the chapel continuously, muttering their prayers as they went. Among these were two men, seemingly father and son, the latter blind. Both were walking round and round the chapel, with their heads uncovered, when the writer arrived, and they were continuing to perform the same wearisome task when he left. One delicate-looking youth, seemingly in consumption, knelt in the mud, for it was mud everywhere around the stone cross already alluded to. He did not move the whole time the reporter was there, and it was obvious that the mode of relief which the poor lad was seeking was too likely to end in accelerating his descent to the grave. (British Medical fournal, 1880.) 